\title{
Educação do Campo: abordagens e tendências no Ensino de Ciências
}

Field Education: approaches and trends in Science Teaching

Education sur le terrain: approches et tendances de L'enseignement des Sciences

Fábio Soares da Paz ${ }^{1}$

Universidade Federal do Piauí

Sandro Rogério Vargas Ustra ${ }^{2}$

Universidade Federal de Uberlândia

Resumo: Este artigo apresenta uma reflexão sobre a articulação dos temas Educação do Campo e Ensino de Ciências a partir de uma análise de artigos publicados na plataforma Scielo. É parte de pesquisa de doutorado em andamento, cujo foco contempla o Ensino de Ciências, Práticas curriculares, Formação e Educação do Campo. Tem como objetivo analisar os artigos da plataforma Scielo na perspectiva do ensino de ciências e da formação de professores para o campo. Utilizou-se uma abordagem metodológica qualitativa de caráter bibliográfico buscando compreender os artigos selecionados através da análise de conteúdo. O estudo aponta para a necessidade de ampliar pesquisas que envolvam a educação do campo e o ensino de ciências na perspectiva multidisciplinar.

Palavras chave: Educação do Campo. Formação de professores. Ensino de Ciências.

Abstract: This article presents a reflection about the articulation of the themes of Field Education and Science Teaching from an analysis of articles published in the Scielo platform. It is part of a doctoral research in progress, whose focus includes Sciences Teaching, Curricular Practices, Training and Field Education. It aims to analyze the articles of the Scielo platform from the perspective of science teaching and teacher training for the field. A qualitative methodological approach of a bibliographic character was used to understand the selected articles through content analysis. The study points to the need to expand research involving field education and the teaching of science in a multidisciplinary perspective.

Keywords: Field Education. Search. Science Teaching.

Résumé: Cet article présente une réflexion sur l'articulation des thèmes de l'enseignement sur le terrain et de l'enseignement des sciences à partir d'une analyse d'articles publiés sur la plateforme Scielo. Il s'inscrit dans le cadre d'une thèse de doctorat en cours portant notamment sur l'enseignement des sciences, la pratique des programmes d'études, la formation et l'enseignement sur le terrain. Il vise à analyser les articles de la plateforme Scielo du point de vue de l'enseignement des sciences et de la formation des enseignants sur le terrain. Nous avons utilisé une approche méthodologique qualitative du caractère bibliographique cherchant à comprendre les articles sélectionnés à travers une analyse de

\footnotetext{
${ }^{1}$ Professor Mestre da Universidade Federal do Piauí (UFPI). Doutorando do Programa de Pós-Graduação em Educação da Universidade Federal de Uberlândia (UFU).E-mail: paz-fabio@hotmail.com

${ }^{2}$ Professor Doutor do Programa de Pós-Graduação em Educação da Universidade Federal de Uberlândia (PPGED/UFU).E-mail: srvustra@ufu.br
} 
contenu. L'étude souligne la nécessité d'élargir la recherche impliquant une formation sur le terrain et l'enseignement des sciences dans une perspective multidisciplinaire.

Mots-clés: L'éducation sur le terrain. Formation des enseignants. Enseignement des sciences

\section{Introdução}

É no envolvimento com a educação do campo e a partir da preocupação com o ensino de ciências especialmente nesse contexto emergente que surge essa investigação. É parte de nossa pesquisa de doutorado cuja delimitação se dá no campo da formação e prática docente na educação do campo. Como resultado de nossas inquietações este estudo tem como objetivo analisar os artigos da plataforma Scielo ${ }^{3}$ observando as discussões sobre ensino de ciências e formação de professores do e no Campo.

Buscando o alcance do nosso objetivo, este trabalho foi dividido em dois tópicos principais. O primeiro aborda os aspectos da formação de professores e os desafios do ensino de ciências no contex to da educação do campo a partir das contribuições vindas da literatura e documentos; o segundo tópico resulta de uma investigação cujo objetivo é analisar artigos sobre a temática publicados na plataforma Scielo. Através da análise de conteúdo, a investigação recai sobre artigos que contemplam o ensino de ciências no contexto da educação do campo, tendo por objeto a produção de conhecimento nessa área.

Por se tratar de algo recente, as reflexões sobre formação, ensino de ciências, currículo e ação docente nesse contexto tornam-se, além de grande desafio, amplamente justificadas. Aliado a isso, tem-se observado em pesquisas recentes (SOUZA, 2008; BRIK et. al., 2014), a existência de lacunas relativas às produções que tratam da educação do campo articulada ao ensino de ciências. Assim, esta pesquisa torna-se relevante e necessária, pois contribui para a discussão sobre os temas, proporcionando reflexões e possibilidades para futuras investigações sobre a temática.

\footnotetext{
${ }^{3}$ A Scientific Electronic Library Online - Scielo é uma biblioteca eletrônica que abrange uma coleção selecionada de periódicos científicos brasileiros. Website disponível em http://www.scielo.br/?lng=pt.
} 


\section{Licenciatura em Educação do Campo: formação de professores e o ensino de ciências}

Molina (2014), ao traçar uma breve contextualização histórica da educação rural no Brasil, evidencia a ausência do Estado na garantia dos direitos no meio rural, entre eles a educação. Somente a partir da promulgação da Constituição brasileira em 1988, seguida pela Lei de Diretrizes e Bases em 1996, que a educação do campo, inicia a desvinculação rural/urbano visando adaptações necessárias à população rural na oferta da educação básica. Essas ações foram provocadas pelas pressões, lutas e articulações dos movimentos sociais que, visando emancipação dos camponeses, assumiram compromisso na luta por políticas públicas de educação voltadas para o campo.

Diante da situação, foi criado em 1998 o Programa Nacional de Educação na Reforma Agrária (PRONERA), voltado à implementação de cursos de graduação associados às especificidades socioculturais, políticas e econômicas do campo. Os cursos de educadores construídos pelo PRONERA vieram a oportunizar debates e posterior consolidação, em 2010, do Programa de Apoio à Formação Superior em Licenciatura em Educação do Campo (PROCAMPO), de forma a instituir as Licenciaturas em Educação do Campo (LIMA, 2017).

Conforme o Ministério da Educação e Cultura (MEC)4, o Procampo tem a missão de promover a formação superior dos professores em exercício na rede pública das escolas do campo e de educadores que atuam em experiências alternativas em educação do campo cujo objetivo é apoiar a execução de cursos regulares de licenciatura em educação do campo nas instituições públicas de ensino superior de todo o país, voltados especificamente para a formação de educadores para a docência nos anos finais do ensino fundamental e ensino médio nas escolas rurais.

O saldo positivo das conquistas históricas dos camponeses, reflete na atualidade e realidade dos 44 cursos de Licenciatura em Educação do Campo, envolvendo 28 universidades federais e 4 institutos em 20 Estados (LIMA, 2017). Entretanto são grandes os desafios da formação de professores do campo cuja concepção de formação é o contexto ao qual o sujeito está inserido. Dessa forma, tornam-se intensas as demandas que possam responder significativamente para a população do campo a estruturação de currículos, teorias pedagógicas, organização didática, educação contextualizada, entre outros desafios presentes nas tensões que envolvem o processo de formação de professores do campo.

\footnotetext{
${ }^{4}$ http://portal.mec.gov.br/tv-mec/programa-de-apoio-a-formacao-superior-em-licenciatura-em-educacao-docampo-procampo.
} 
As dificuldades enfrentadas pelos cursos de formação de professores em educação do campo na área de ciências da natureza estão presentes desde a epistemologia da prática docente a materialização das práticas educativas. Apesar do Procampo situar suas políticas públicas de educação no combate às desvantagens educacionais sofridas pela população rural, ainda é insuficiente, haja vista, entre outros, os aspectos de sua história recente ao lado das grandes demandas e especificidades.

É preciso formar professores de ciências não somente para atuar no campo, mas para atuar de forma completa na educação do campo, considerando seus princípios e demandas numa articulação necessária entre a área de educação em ciências e a emergente área de educação do campo (BRICK, et, al., 2014). São obstáculos que vão desde a formação de professores que atuam nas LEdoCs $^{5}$ às práticas docentes realizadas, caracterizados pela formação tradicional em campos de conhecimentos específicos dentro do contexto urbano, aos poucos subsídios encontrados na literatura sobre o Ensino de Ciências, Ensino de Física, que tenham relações explícitas com a educação do campo.

Torna-se bastante desafiador para a Instituição de Ensino Superior (IES) promover uma formação comprometida com o ensino de ciências interdisciplinar e multidisciplinar para atuação nos níveis Fundamental e Médio em escolas do campo, haja vista o predomínio nessas instituições da formação tradicional. Da mesma forma o professor formador é desafiado a pensar novas formas de ensinar. Nesse sentido, ao propor uma formação docente multidisciplinar, a Educação do Campo requer do corpo docente das instituições a realização de práticas articuladas através de trabalho orgânico, coletivo, integrado e contextualizado.

No caso específico da formação de professores para ensinar ciências, em pauta o ensino das Ciências Físicas, Astolfi e Develay (1991), indicam como característica a especificidade da profissão de professor, onde deve dispor de ferramentas buscadas em situações educativas. Britto (2011) divulga a necessidade de pensar uma educação em ciências que esteja a serviço do projeto da Educação do Campo. Ferreira e Molina (2014) acenam para uma educação capaz de produzir teorias e práticas para construção de novos sujeitos. Esses pensamentos convergem para uma educação que possibilite sujeitos historicamente excluídos às pessoas com direitos garantidos dentro da sua perspectiva, de sua diversidade, num contexto em que o homem do campo seja o protagonista.

\footnotetext{
${ }_{5}^{5}$ Trata-se dos professores que atuam em cursos de Licenciatura em Educação do Campo.
} 


\section{Desafios para o ensino de ciências}

Os desafios dos cursos de Licenciatura em Educação do Campo, cuja especificidade é formar professores para atuar no ensino de ciências, podem ser pensados a partir da demanda das diretrizes de formação desses cursos e do contexto da educação do campo. Estes documentos apontam para os importantes desafios que vão desde o reconhecimento de formas alternativas de organização dos tempos e espaços escolares até a definição de estratégias e materiais para o ensino do campo. (BRASIL, 2012). As dificuldades se dão na perspectiva dos pressupostos da educação do campo que, conforme Caldart (2012) trata-se da combinação de pedagogias de modo a fazer uma educação que cultive saberes, identidades, auto-estima, valores, memórias; numa projeção de movimentos, relações, transformações.

Portanto, emerge a formação do professor em ciências como desafio para a Licenciatura em Educação do Campo. Uma formação para atuar na Educação do Campo deve apontar para o bojo de políticas públicas de educação que atendam às diretrizes operacionais e as diretrizes político-pedagógicas. Essas diretrizes adquirem forma na matriz curricular do curso das licenciaturas propondo uma formação docente multidisciplinar organizada pela prática curricular da pedagogia da alternância.

Por outro lado, apesar da educação do campo se configurar como uma política de estado atuando por meio de programas como Pronera, o Pronacampo e o Procampo, o enfrentamento para sanar as necessidades formativas de professores de ciências para atuarem nas escolas do campo ainda está sendo iniciada historicamente. (BRICK et al., 2014). Esses autores pontuam as poucas obras existentes na literatura sobre o Ensino de Ciências, Ensino de Física, relacionadas à Educação do Campo.

Nesse contexto, Brito (2011), destaca que o exercício da docência tem exigido intensa dedicação nas atividades de ensino, pesquisa e extensão, primeiro por se tratar de um curso novo, e segundo pelos condicionamentos de formação em contex to urbano. Entre os desafios: 1) práticas pedagógicas multidisciplinares e contextualizadas; e 2) Planejamento coletivo que considere os sujeitos concretos. (BRICK et al., 2014). Acrescentamos ainda os desafios teórico-práticos: interdisciplinaridade, pesquisa, estágio coletivo, diálogo e articulação do ensino de ciências com os princípios da educação do campo.

Os dados do Instituto Nacional de Estudos e Pesquisas Educacionais Anísio Teixeira (INEP), sobre formação de professores do campo reafirmam urgência do enfretamento das problemáticas na efetiva implementação das políticas públicas do Campo (PAZ, 2017). 
Considerando a zona rural/campo, em níveis de formação, apenas 21,6\% dos professores que atuam no fundamental de $1^{\mathrm{a}}$ a $4^{\mathrm{a}}$ série têm formação superior. Nas urbanas esse número sobe para 56,4\%! (INEP, 2007). No estado do Piauí, por exemplo, são 1.553 professores apenas com Ensino Fundamental como maior grau de escolarização, sendo 19.038 os que possuem apensas o nível de Ensino Médio (UFPI, 2013). Situação que se agravada no interior do estado e nas escolas do campo, onde o déficit de professores torna-se mais prioritário nas áreas de Física, Química, Ciências Biológicas e Matemática.

Reconhecendo os desafios a serem enfrentados e considerando as políticas do Ministério da Educação e o esforço dos Movimentos Sociais, entidades, secretarias entre outros, para efetivo sucesso na formação de professores do campo, são necessárias ações concretas para sanar as lacunas quanto-qualitativas de formação, bem como assegurar a especificidade de formação dos povos do campo ( PAZ, 2017).

\section{Metodologia}

A investigação levada a cabo caracteriza-se no campo teórico-metodológico como pesquisa bibliográfica de natureza qualitativa, objetivando levantar, analisar e discutir a produção acadêmica na área da educação do campo. A pesquisa no banco de dados da plataforma Scielo foi realizada com os termos de busca: "educação do campo" e "pedagogia da alternância”. Logo após foram selecionados os artigos que se relacionam ao ensino de ciências e aos princípios da educação do campo.

Os dados foram analisados e divididos em categorias correspondentes ao objeto de estudo segundo análise de conteúdo ${ }^{6}$ na perspectiva de Bardin (2011). Dessa forma, usamos três etapas fundamentais dessa perspectiva: pré-análise (etapa em que se processa a organização do material, ou seja, os dados necessários à concretização do estudo); descrição analítica (etapa em que se apresentam as informações existentes no material através de análise profunda) e, finalmente, a interpretação inferencial que consiste em reflexão, a fim de se estabelecerem relações com a realidade pesquisada, realizando-se as inferências

\footnotetext{
${ }^{6} \mathrm{~A}$ análise de conteúdo constitui uma metodologia de pesquisa usada para descrever e interpretar o conteúdo de toda classe de documentos e textos. Conduz a descrições sistemáticas, qualitativas ou quantitativas, ajuda a reinterpretar as mensagens e a atingir uma compreensão de seus significados num nível que vai além de uma leitura comum. Têm sido cada vez mais valorizadas as abordagens qualitativas, utilizando especialmente a indução e a intuição como estratégias para atingir níveis de compreensão mais aprofundados dos fenômenos que se propõe a investigar. Entretanto, qualquer de suas abordagens fornece informações complementares ao leitor crítico de uma mensagem, seja ele lingüista, psicólogo, sociólogo, educador, crítico literário, historiador ou outro (MORAES, 1999).
} 
necessárias.

O corpus foi composto de artigos pesquisados, primeiramente, com a temática educação do campo e pedagogia da alternância, num total de 37 trabalhos. Em seguida foi feita correlação com o ensino de ciências, convergindo no total de 04 trabalhos, classificados e organizados pelo resumo de cada obra sendo descrito em quadro geral os seguintes aspectos: ano, objetivo, metodologia e resultados.

\section{Análise e Discussão}

\section{Elaboração das categorias de análise}

A análise de conteúdo é um conjunto de técnicas de análises de comunicações, cuja importância se dá na pesquisa do sentido do texto balizado por duas fronteiras: da lingüística tradicional e na abordagem no campo interpretativo do sentido das palavras. Para Bardin (1977) a importância do rigor na utilização da análise de conteúdo vem da necessidade de ultrapassar as incertezas das fontes analisadas utilizando procedimentos sistemáticos e objetivos de descrição dos conteúdos das mensagens. Entretanto alguns erros podem ocorrer quando os cuidados metodológicos exigidos não são devidamente aplicados, implicando principalmente, para pesquisadores iniciantes, a prática intuitiva e não sistematizada (SIVA; FOSSÁ, 2015).

Observando o contexto da aplicabilidade da análise de conteúdo, discutimos os aspectos gerais da análise sistematizando e organizando o material estudado de modo estruturarando as perguntas norteadoras que auxiliaram no processo de criação das categorias.

\section{Perguntas Norteadoras}

Após elaboração e organização das perguntas norteadoras ${ }^{7}$, e para facilitar 0 agrupamento, compomos as categorias iniciais como parte da primeira impressão da realidade organizacional estudada. $\mathrm{O}$ conjunto das categorias iniciais analisadas foi agrupado

\footnotetext{
${ }^{7}$ Conforme os pressupostos da análise de conteúdo, a criação das categorias teve como ponto de partida as perguntas norteadoras, no intuito de facilitar os procedimentos: agrupamentos, classificações e a pré-análise. Utilizamos esses procedimentos conforme Franco (2008); Silva e Fossá (2015), pois são vistos como indispensáveis e fundamentais para auxiliar a posterior criação de categorias e, consequentemente, a inferência, análise e interpretação de dados.
} 
nas categorias intermediárias, por fim, nesse processo de diálogo com nosso objeto de estudo, estruturamos as categorias finais de análise: 1) Fundamentos da pesquisa; 2) Aspectos Teórico-Metodológicos; 3) Especificidades envolvendo ensino de ciências e educação do campo.

\section{Fundamentos da Pesquisa}

Partindo do pressuposto de que as pesquisas que discutem educação do campo e ensino de ciências revelam faces contraditórias em relação às diretrizes vigentes na educação brasileira em contextos específicos, se faz necessário um levantamento dessas questões. São pesquisas que tratam da necessidade em articular o ensino das ciências nas especificidades da educação do campo, em que é unânime a aplicação de práticas diferenciadas para o campo, de forma que, todas defendem mudanças estruturais e curriculares nessa perspectiva.

Porém é importante evidenciar as fragilidades existentes nas pesquisas no que diz respeito à singularidade do campo e as bases históricas do ensino de ciências no Brasil. As pesquisas que abordam o ensino de ciências na educação do campo exploram algumas lacunas que também pertencem ao ensino urbano. A XI Conferência Interamericana (MOREIRA, 2017) sobre desafios no Ensino de Física já enfatizava a problemática do despreparo de professores, condições de trabalho, fragmentação do currículo, escasso número de aulas, ensino descontextualizado e ênfase no livro texto. Esses desafios são vistos de forma geral no ensino de ciências. Dessa forma as pesquisas revelam fragilidades no que diz respeito ao posicionamento crítico e bem delimitado sobres as fronteiras existentes entre o ensino urbano e o ensino campesino. Sobretudo, é observada uma situação de exigências à educação do campo de forma que as evidências se aplicam ao ensino de educação em ciências.

Quanto aos problemas de pesquisa, no âmbito do ensino das ciências, partimos do pressuposto de que são delineados pelas exigências que "migraram" dos desafios que esse ensino participa nos contextos urbanos. Muitos pesquisadores em educação do campo/ensino de ciências ainda padecem com poucos materiais de pesquisa fundamentada nessa área, recorrendo, então, às pesquisas em educação em ciências. Dessa forma, a base das pesquisas que envolvem o ensino de ciências na educação do campo, pela sua pouca história, consequentemente poucos subsídios na literatura, desperta inquietações e dúvidas epistemológicas nos pesquisadores.

Observando as palavras-chaves, três artigos têm em comum as palavras Educação do 
Campo e Ensino de Ciências, enquanto o quarto trabalha com Área Educação do Campo e Ciências da Natureza. Temos que metade dos trabalhos focam no estudo sobre currículo e conteúdo, enquanto a outra metade trabalha com investigação sobre temáticas específicas (agrotóxicos e energia). O que evidencia a preocupação dos autores com indicativos de ensino pautado por investigação temática, mudanças curriculares e abordagens sobre conteúdo.

Outro aspecto importante nos trabalhos analisados: nenhum deles apresenta “contextualização histórica” da educação do campo. Tal característica caminha em oposição ao que pontua Souza (2008), que ao analisar produções de mestrado e doutorado observou repetições muito semelhantes no quesito "histórico", considerando ser um desafio para os novos pesquisadores à superação da dimensão da reprodução daquilo exaustivamente já dito. Entretanto observamos valorização do objeto de estudo à procura de novos conhecimentos. Essas investigações são divididas igualmente no lócus das escolas do campo e nos cursos de Licenciatura do Campo.

\section{Aspectos Teórico-Metodológicos}

Todos os trabalhos têm como característica metodológica a abordagem qualitativa de pesquisa. As técnicas de coletas de dados têm sido caracterizadas por Narrativa, Entrevista e Questionário. Quanto ao método de análise apenas um texto deixa bem definido, ao trabalhar Análise Textual Discursiva - ATD. Os outros textos trabalham na perspectiva teórica da análise de conteúdo. O predomínio da abordagem qualitativa sinaliza com pesquisas mais robustas (SOUZA, 2008); (SOUZA, 2007), nas quais foram analisadas mais de 150 teses e dissertações que trataram de pesquisas relacionadas a educação e/no Movimento dos Trabalhadores Rurais Sem Terra (MST), privilegiando, na sua maioria, os aspectos qualitativos.

\section{Especificidades Envolvendo o Ensino de Ciências e Educação do Campo}

Do ponto de vista teórico, as pesquisas indicam discussões na vertente interdisciplinar e contextualizada de assuntos e conteúdos do ensino de ciências. Os autores Demétrio Delizoicov, Décio Auler, Maria Marta Pernambuco e Attico Chassot que tratam do ensino de ciências estão entre os mais citados. São autores expressivos na área da educação em ciências. Os autores Roseli Salete Caldart, Miguel Arroyo e Néli Suzana Brito são bastante citados no 
foco da educação do campo. Da educação o mais citado é Paulo Freire, geralmente como aporte teórico para pedagogia do campo e/ou educação, na sua obra pedagogia do oprimido.

O papel conferido à educação do campo vem dialogando nas obras com uma formação docente que ultrapasse as barreiras disciplinares constituintes das áreas de conhecimento capaz de envolver as diversas dimensões do campo. Tem como objetivo trabalhar as disciplinas curriculares interligando aspectos sociais e pessoais dos estudantes e envolve-los no desenvolvimento de relações que estreitem as vivências do campo e os conceitos científicos, bem como romper com a visão fragmentada do processo de produção do conhecimento.

As dificuldades para a compreensão da ciência conduzem a problematização da realidade do campo através da sua especificidade cotidiana e tradições como barreira para a compreensão da ciência, somado com o distanciamento provocado pelo livro didático à realidade do aluno. Acrescentam-se ainda as dificuldades dos discentes na relação de envolvimento dos conteúdos específicos através da abordagem temática com o papel dos movimentos sociais no contexto das lutas sociais da educação do campo. Como a educação do campo valoriza os sujeitos do campo em suas mais variadas formas de organização, particularidades e cultura como práxis, é pertinente afirmar que sua especificidade no contexto do ensino de ciências deve desenvolver-se também no entrelaçamento de todos os sujeitos e grupos campesinos.

Os conteúdos que marcam as pesquisas em ensino de ciências e educação do campo estão dispostos nas pesquisas em três temas que se interligam. A Investigação Temática é trabalhada com o tema agrotóxico no ensino de ciências. A educação Intercultural é abordada no exercício do conceito de energia, e o estudo da realidade como prática do ensino de ciências através de percursos formativos em diálogos Freireanos.

As principais críticas são voltadas para o modelo de formação vigente nas universidades brasileiras considerando aspectos ilustrativos das ciências, lógica hegemônica disciplinar, fragmentação, isolamento e separação dos conteúdos das ciências Físicas, Químicas, Biológicas. Quanto ao ensino, mantêm-se as críticas que pertencem também ao escopo da escola urbana. Ensino centrado no professor, abordagem da ciência de forma neutra e informativa, livresca e conteudista. Ensino focado apenas nos produtos da ciência e ao modelo positivista nessa abordagem. As críticas que se alinham aos princípios da educação do campo implicam no enfrentamento da visão salvacionista que outorga a ciência e a tecnologia solução de problemas de diferentes ordens e a visão tecnocrata científica de que só 
podem tratar de ciência e tecnologia especialistas.

\section{Considerações Finais}

Ponderando quanto à complexidade do tema, julgamos importante a continuidade de análises sobre a produção bibliográfica sobre os temas em foco, haja vistas ser recente a proposição de formação inicial de professores em Educação do Campo na área de ciências da natureza.

Através da análise dos artigos da plataforma Scielo, de leituras e estudos mais amplos realizados, cumpre registrar a tendência crescente na publicação de obras sobre educação do campo. Entretanto, a pesquisa evidencia a baixa produção sobre o Ensino de Ciências neste contexto.

Embora a análise tenha apontado para um número bastante reduzido de trabalhos sobre o ensino de ciências na interface com educação do campo, fica evidenciada nos objetivos dos trabalhos a preocupação com a contextualização da educação (de modo geral), indicando reflexões sobre o currículo e modificações das práticas tradicionais, uma vez que esse movimento está de acordo com os princípios e diretrizes da educação do campo.

Dessa forma, partimos do pressuposto que os conteúdos trabalhados na escola contribuem para emancipação do sujeito enquanto cidadão de um mundo cada vez mais agressivo tecnologicamente. A compreensão desse mundo, no contexto rural/campo, não menos importante que o urbano/cidade, torna-se imprescindível, quanto à parte da relevância da melhor/maior participação do sujeito e sua interação com o ambiente social.

Urge, portanto o desenvolvimento de pesquisas que contribuam para as discussões sobre o ensino de ciências que tenham divulgação em plataformas como a Scielo, dentre outras. Nesse sentido, destacamos a importância de pesquisas relacionadas às ciências Físicas, Químicas e Biológicas no âmbito das ações dos cursos de Licenciatura em Educação do Campo, e também pesquisas relacionadas às atividades de extensão e ensino nas escolas do campo, sempre em parceria com as Instituições de Ensino Superior.

\section{Agradecimentos}

Os autores deste trabalho agradecem à CAPES o apoio recebido através da bolsa Edital 023/2014 CAPES/DINTER Programa de Bolsas de Doutorado INTERINSTITUCIONAL. 


\section{Referências}

BARDIN, L. Análise de conteúdo. Lisboa: Edições 70, 2011.

BRASIL. Ministério da Educação.Secretaria de Educação Continuada, Alfabetização, Diversidade e Inclusão - SECADI. Educação do Campo: marcos normativos. Brasília: SECADI, 2012.

BRICK, E. M.; PERNAMBUCO, M. M. C. A.; SIlvA, A. F. G. da.; DelizOICOV, D.; Paulo Freire: interfaces entre ensino de ciências naturais e educação do campo. In: MOLINA, M. C. (Org). Licenciaturas em Educação do Campo e o ensino de Ciências Naturais: desafios à promoção do trabalho docente interdisciplinar. Brasília: MDA, p. 23-59, 2014.

BRITTO, N. S. Formação de professores e professoras em Educação do Campo por área do conhecimento - Ciências da Natureza e Matemática. In: MOLINA, M. C.; SÁ, L. M. (Orgs.) Licenciaturas em Educação do Campo: registros e reflexões a partir das experiências-piloto (Coleção caminhos da Educação do Campo 5). Belo Horizonte: Autêntica, 2011.

CALDART, R. S.; PEREIRA, I. B.; ALENTEJANO, P.; FRIGOTTO, G. Apresentação. In:_ Dicionário da Educação do Campo. Rio de Janeiro, São Paulo: Escola Politécnica de Saúde Joaquim Venâncio, Expressão Popular, p. 13 - 19, 2012.

FERREIRA, M. J. L; MOLINA, M. C. Desafios à formação de educadores do campo: tecendo algumas relações entre os pensamentos de Pistrak e Paulo Freire. In: MOLINA, M. C.; (Org). Licenciaturas em Educação do Campo e o ensino de Ciências Naturais: desafios à promoção do trabalho docente interdisciplinar. Brasília: MDA, p. 64-153, 2014.

INEP. Instituto Nacional de Estudos e Pesquisas Educacionais. Panorama da educação do campo 2007. Brasília: Inep, 2007.

LIMA E. de S. Apresentação. In; PAZ, Fábio S. da.; ARRAIS, G. de A.; MOTA, L. A. (Org.). Experiências em educação do campo. Teresina: EDUFPI, p. 12-19, 2007.

MOLINA, M. C. Expansão das licenciaturas em educação do campo: desafios e potencialidades. Educar em Revista, Curitiba, n. 55, p. 145-166, jan./mar. 2015.

MORAES, R. Análise de conteúdo. Revista Educação, Porto Alegre, v. 22, n. 37, p. 7-32, 1999.

MOREIRA, M. A. Grandes desafios para o ensino da física na educação contemporânea. Revista do Professor de Física, Brasília, vol. 1, n. 1, 2017.

PAZ, F. S. da; OLIVEIRA, S. R. M.. de. Reflexões sobre o ensino de física na educação do Campo. In; PAZ, Fábio S. da.; ARRAIS, G. de A.; MOTA, L. A. (Org.). Experiências em educação do campo. Teresina: EDUFPI, p. 72-88, 2007.

SOUZA, M. A. Educação do campo: políticas, práticas pedagógicas e produção científica. Revista Educ. Soc., Campinas, vol. 29, n. 105, p. 1089-1111, set./dez., 2008.

SILVA, A. H.; FOSSÁ, M. I. T. Análise de conteúdo: exemplo de aplicação da técnica para 
Revista Educação e Políticas em Debate - v. 7, n. 3, p. 550-562, set./dez. 2018 - ISSN 2238-834

análise de dados qualitativos.Qualit@s Revista Eletrônica, Campina Grande, vol.17.n. 1, 2015.

UNIVERSIDADE FEDERAL DO PIAUÍ. Projeto Pedagógico do Curso de Licenciatura em Educação do Campo, 2013. 